\title{
Feasible laparoscopic distal pancreatectomy for pancreatic neuroendocrine tumors
}

\author{
HIRONORI SHIOZAKI, YOSHIHIRO SHIRAI, TAKASHI HORIUCHI, JUNGO YASUDA, \\ KENEI FURUKAWA, SHINJI ONDA, TAKESHI GOCHO, HIROAKI SHIBA and TORU IKEGAMI \\ Department of Surgery, The Jikei University School of Medicine, Minato-ku, Tokyo 105-8461, Japan
}

Received October 10, 2020; Accepted February 15, 2021

DOI: $10.3892 / \mathrm{mco} .2021 .2273$

\begin{abstract}
Pancreatic neuroendocrine tumor (PNET) cases are increasing; however, the treatment indication and procedure remain unestablished. The present study evaluated the indication, feasibility and safety of laparoscopic distal pancreatectomy (LDP) with our technique for PNET. A total of 13 patients with insulinoma and nonfunctional PNET $<2 \mathrm{~cm}$ in diameter who underwent LDP and 13 patients with any size of PNET who underwent open distal pancreatectomy (ODP) between October 2009 and June 2019 were retrospectively reviewed and compared. The median age of patients was 45 (33-61) years, and 14 (54\%) patients were male. The median follow-up periods were 70 months for the LDP group and 46 months for the ODP group. The tumor diameter of the patients who underwent LDP for PNET was $18 \pm 9 \mathrm{~mm}$ compared with $37 \pm 25 \mathrm{~mm}$ for those who underwent ODP. The operation time, estimated blood loss, and complication were $290.2 \pm 115$ vs. $337 \pm 131 \mathrm{~min}$ $(\mathrm{P}=0.338), 122 \pm 172$ vs. $649 \pm 693 \mathrm{ml}(\mathrm{P}=0.019)$ and 31 vs. $54 \%(\mathrm{P}=0.234)$, respectively. Pancreatic fistula developed in $8 \%$ of patients who underwent LDP compared with $31 \%$ who underwent ODP $(\mathrm{P}=0.131)$. Notably, the postoperative hospitalization period was significantly shorter in the LDP group ( $11 \pm 7$ vs. $21 \pm 13$ days; $\mathrm{P}=0.022)$. Tumor grade of 2017 World Health Organization classification (G1/G2/G3/NEC/unknown) was 9/2/0/0/2 for the LDP group compared with 5/5/0/3/0 for the ODP group. Furthermore, lymph node metastasis was detected in only 1 patient who underwent ODP, for whom the maximum tumor diameter was $70 \mathrm{~mm}$ and was classified as $\mathrm{G} 2$. In addition, 2 patients in the ODP group developed postoperative lung and liver metastases. LDP for PNETs of $<2 \mathrm{~cm}$ in selected patients
\end{abstract}

Correspondence to: Dr Hironori Shiozaki, Department of Surgery, The Jikei University School of Medicine, 3-25-8 Nishi-shinbashi, Minato-ku, Tokyo 105-8461, Japan

E-mail: hironori525@hotmail.co.jp

Key words: laparoscopic surgery, neuroendocrine tumor, pancreatectomy can be safely performed; however, the extent of lymph node dissection needs to be clarified.

\section{Introduction}

Pancreatic neuroendocrine tumor (PNET) arising from neuroendocrine cells throughout the body of pancreas is rare cancer. This type of cancer accounts for 1-3\% of all pancreatic cancer and $\sim 85 \%$ of the cases are designated as nonfunctional tumors which do not secrete clinically significant hormones, whereas $15 \%$ of the cases are known as functional PNET which secrete hormones leading to clinical symptoms (1). However, the incidence of PNET has been increasing by $\sim 1,000$ new patients every year (2). A total of 3,379 patients received treatment for PNET, and the annual prevalence of PNET in 2010 is estimated to be 2.69 per 100,000 population, which is $\sim 1.2$ times higher than that in 2005 according to a nationwide epidemiological survey in Japan (3). Overall they have a better prognosis than common pancreatic cancers, and 5-year survival rate of localized and resected tumors is $\sim 55 \%$ (1). However, 5-year survival rate of unresectable tumors is only $\sim 15 \%(1,2)$. The National Comprehensive Cancer Network guideline, as well as the European Neuroendocrine Tumor Society (ENETS) guideline, recommends the resection of all locoregional PNET cases $(4,5)$.

The newest version of the World Health Organization classification system established in 2017 are classified as well-differentiated tumors or poorly differentiated tumors, with grading based on the mitotic count and/or the Ki-67 labeling index. PNETs with well-differentiated histology include those of grade 1 (G1) and grade 2 (G2) as well as a new subset of grade 3 (G3). Poorly differentiated pancreatic neuroendocrine carcinomas are those with G3 histology called as pancreatic neuroendocrine carcinoma (PNEC) (1).

Laparoscopic distal pancreatectomy (LDP) has been covered by insurance since 2012 in Japan. LDP with lymph node dissection just around pancreas has been one of the treatment options for insulinoma and nonfunctional PNET of $<2 \mathrm{~cm}$ in our hospital because insulinoma are almost benign and nonfunctional PNET of $<2 \mathrm{~cm}$ have a small risk of lymph node metastases (6-13).

LDP with lymph node dissection just around pancreas appears to be technically simple procedure enough to 
innovate the laparoscopic pancreatectomy for young surgeon and institution with less experience of this procedure.

We, therefore, hypothesized that LDP with lymph node dissection just around the pancreas would provide a safe and good short-term outcome for insulinoma and nonfunctional PNET of $<2 \mathrm{~cm}$.

\section{Patients and methods}

Patient selection. We identified patients from our prospectively maintained database in Department of Hepato-Biliary-Pancreatic Surgery at Jikei University Hospital between Oct, 2009 and Jun, 2019. Twenty-six patients with PNET who underwent distal pancreatectomy were analyzed. We performed a retrospective review of these patients who were histologically diagnosed with PNET. Preoperative diagnosis and size determination were performed using CT, MRI, somatostatin scintigraphy, and endoscopic ultrasound (EUS) with or without guided fine needle aspiration (FNA), and tumor function was determined by various hormone tests and SASI tests. Pathological findings and tumor grade were based on the World Health Organization Classification 2017 for Pancreatic Neuroendocrine Neoplasms. The medical records were analyzed retrospectively for patient age, gender, performance status (PS), Body mass index (BMI), Tumor size, WHO grade, function, operation time, estimated intraoperative blood loss, blood transfusion, residual tumor, lymph node metastasis, complications (such as hemorrhage, pancreatic fistula, intra-abdominal abscess, and surgical site infection) as well as postoperative hospitalization period among the patients in the two groups i.e., those who underwent laparoscopic surgery and those who underwent open surgery. The PS was classified as per the classification system by The American Society of Anesthesiologist (ASA).

Treatment. Patients with insulinoma or nonfunctional PNET of $<2 \mathrm{~cm}$ underwent LDP with lymph node dissection just around the pancreas. Patients who displayed other kinds of PNET or those with nonfunctional PNET $>2 \mathrm{~cm}$ underwent open distal pancreatectomy (ODP) with systematic lymph node dissection. All procedures were performed by hepato-biliary-pancreatic surgeons of our department. Later, patients had an imaging study and blood tests performed every 3 months for 5 years in follow-up clinic.

LDP technique. Under general endotracheal anesthesia, patients were placed in a supine position. In laparoscopic pancreatectomy, an umbilical scope trocar and four trocars (two $12 \mathrm{~mm}$ and two $5 \mathrm{~mm}$ trocars) were utilized. The surgical field was prepared by placing the table in a reverse Trendelenburg position, which was slightly rotated to the bottom right. Then, the greater omentum was opened toward the craniad of the spleen with a dissection of the left gastroepiploic and the short gastric vessels through the greater curvature and toward the caudad of the spleen with a dissection of the splenicocolic ligament to prevent injuring the transverse colon. Next, the retroperitoneum was dissected below and lateral of the spleen. The posterior stomach wall was then fixed to the abdominal wall to enable viewing of the omental bursa and pancreas. The superior mesenteric vein was identified from the colic vein, and the pancreas was tunneled right above the portal vein. Thereafter, the splenic artery was isolated and ligated first (artery-first technique), followed by transecting the pancreas right above the portal vein with a triple-row stapler. The partial pancreatectomy site, particularly on the left side merely above the portal vein, was then transected. Subsequently, the retropancreatic plane on the Toldt's fascia was dissected from the caudad to the craniad of the pancreas; the lymph nodes were also dissected around the pancreas and spleen. After the complete resection of the specimen containing the body and tail of the pancreas and spleen, it was removed using an endobag through the umbilical wound with or without prolongation. After the hemostasis and injury were reviewed, a drain was positioned around the pancreas stump. (shown in Fig. 1).

Statistical analysis. Data is expressed as mean \pm standard deviation (SD). Differences in the continuous data were compared using Student's t-test. Differences between other characteristics with small sample sizes were tested using chi-square test or Fisher's exact test. P-values were considered statistically significant when $<0.05$. All statistical tests were performed using the SPSS software package (v 23.0).

\section{Results}

Patient characteristics. Thirteen patients who underwent LDP and 13 patients who underwent ODP were identified. Table I shows the patient characteristics, such as their age, gender, and BMI, which were found to be comparable between the LDP and ODP groups. Patients were primarily with low PS scores $(1 ; 77 \%)$ in LDP group and patients were with low PS scores $(1 ; 54 \%)$ in OP group with no statistical difference. Tumor diameter in LDP group tended to be smaller than that in the ODP group as an indication of laparoscopic surgery. According to WHO grade, eleven patients of G1 and two patients of G2 in LDP group, and five patients of G1, five patients of $\mathrm{G} 2$, and three patients of pancreatic neuroendocrine carcinoma (PNEC) in ODP group were classified. Two patients with insulinoma include LDP group and 1 patient with gastrinoma were included in the ODP group. Tumor function in all patients was diagnosed by preoperative hormonal tests. They did not exhibit lymph node enlargement in preoperative diagnostic imaging.

Surgical factors and postoperative outcomes. As shown in Table II, Distal pancreatectomy required 290.2 \pm 114.6 and $337.3 \pm 130.7$ min to be performed in the LDP and ODP groups, respectively, with no statistical difference. Of note, the estimated blood loss in the LDP and ODP groups was $122.3 \pm 171.8$ and $649.2 \pm 692.6 \mathrm{ml}$, respectively, which was statistically significant. Meanwhile, requirement for blood transfusion and residual tumor was very similar among the two groups. Regarding complications, SSI in LDP group trended to be fewer than that in ODP group, with no statistical difference, and the overall complications were found to be similar. Postoperative hospitalization periods were statistically longer 
A

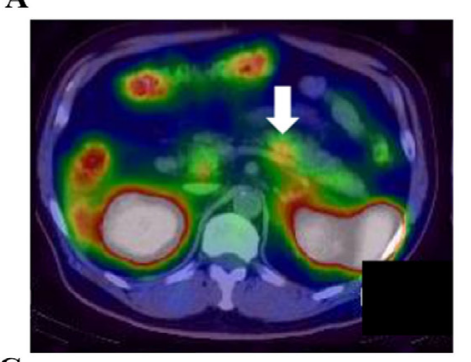

C

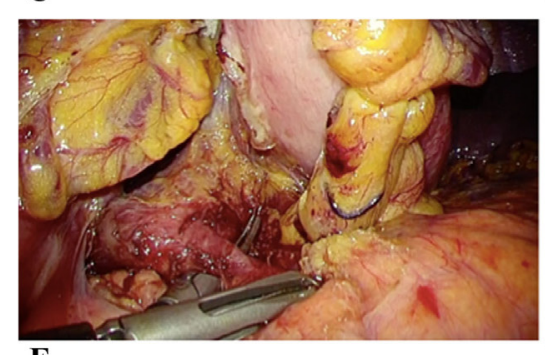

E

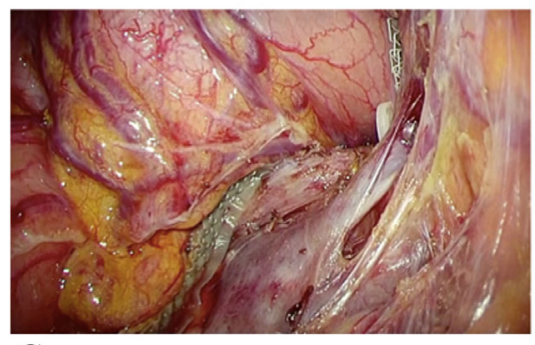

G

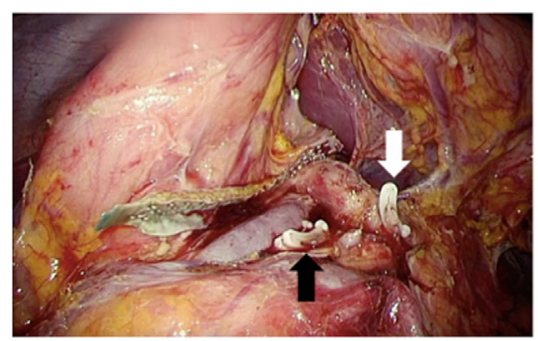

B

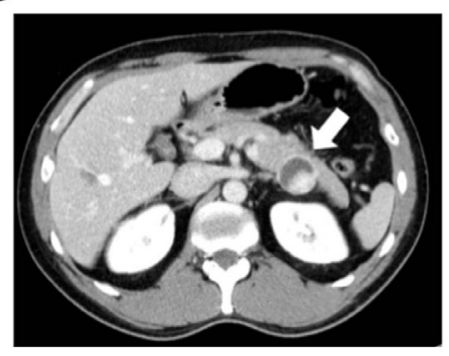

D

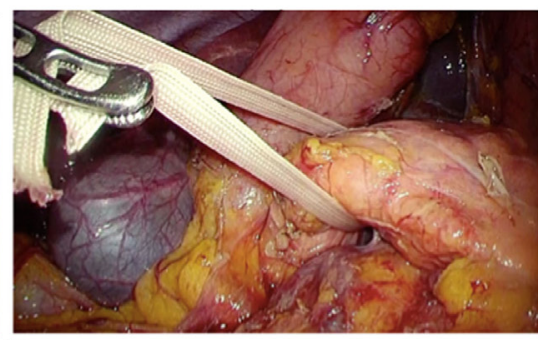

F

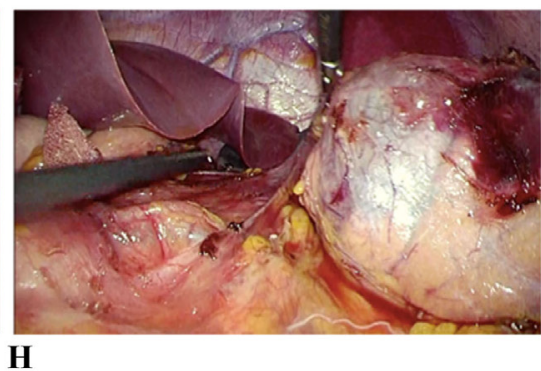

H

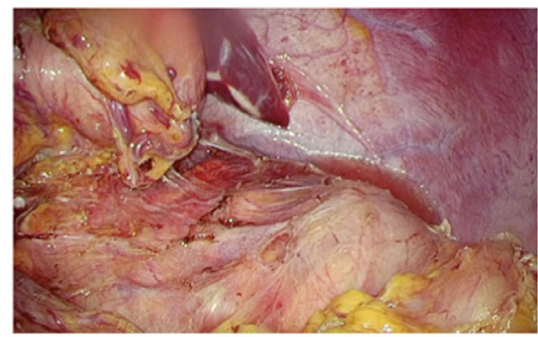

Figure 1. Technique of laparoscopic distal pancreatectomy. (A) Insulinoma, somatostatin receptor scintigraphy. The white arrow indicates the tumor. (B) Nonfunctional neuroendocrine tumor $<2 \mathrm{~cm}$. The white arrow indicates the tumor. (C) First dissection of the splenic artery. (D) Taping and dissection of the pancreas. (E) Encirclement and dissection of the splenic vein. (F) Abruption of the pancreas on the Toldt's Fascia. (G) After pancreatectomy. The white arrow indicates the cut end of the splenic artery. The black arrow indicates the cut end of the splenic vein. (H) After pancreatectomy (preserving the Gerota's fascia).

Table I. Patient characteristics.

\begin{tabular}{|c|c|c|c|}
\hline Factor & $\begin{array}{c}\text { LDP } \\
(n=13)\end{array}$ & $\begin{array}{c}\text { ODP } \\
(n=13)\end{array}$ & P-value \\
\hline Age, years ${ }^{\mathrm{a}}$ & $47.9 \pm 11.0$ & $50.2 \pm 15.8$ & 0.670 \\
\hline Sex, n (male:female) & $7: 6$ & $7: 6$ & $>0.999$ \\
\hline ASA score, $\mathrm{n}(1: 2)$ & $10: 3$ & $7: 6$ & 0.205 \\
\hline $\mathrm{BMI}, \mathrm{kg} / \mathrm{m}^{2}$ & $23.1 \pm 4.0$ & $23.6 \pm 4.6$ & 0.806 \\
\hline Tumor diameter, mm & $19.9 \pm 9.9$ & $35.0 \pm 25.0$ & 0.060 \\
\hline $\begin{array}{l}\text { WHO grade, } \mathrm{n} \\
(\mathrm{G} 1: 2: 3: \mathrm{NEC})^{\mathrm{b}}\end{array}$ & $11: 2: 0: 0$ & $5: 5: 0: 3$ & 0.154 \\
\hline Function, n (yes:no) & $2: 11$ & $1: 12$ & 0.500 \\
\hline
\end{tabular}

${ }^{\mathrm{a}}$ Mean $\pm \mathrm{SD}$; ${ }^{\mathrm{b}} 2$ unknown cases. ASA, The American Society of Anesthesiologist; WHO, World Health Organization; NEC, neuroendocrine carcinoma; LDP, laparoscopic distal pancreatectomy; ODP, open distal pancreatectomy. in the ODP group than that in the LDP group. This was also a feature of the laparoscopic procedure which is described in Table III.

We found that only one patient from the ODP group had developed metastases of the dissected lymph node, as described in Table IV. This patient, who had been diagnosed with gastrinoma, underwent partial pancreatectomy with systematic lymph node dissection. Pathological findings showed that it was a $6 \mathrm{~mm}$ G1 gastrinoma, and she displayed no recurrence after surgery for the next 3 years.

Further, two patients from the ODP group, developed recurrence of PNET, are described in Table IV. These were male patients in their 40s and had been diagnosed with nonfunctional PNET, and they underwent distal pancreatectomy with lymph node dissection. Pathological findings discovered PNETs of 41 and $20 \mathrm{~mm}$ in the two patients. Further, a recurrence of liver metastases was detected at 1 and 21 months, respectively, after surgery in the two patients. 
Table II. Surgical and pathological factors.

\begin{tabular}{lccc}
\hline Factor & LDP $(\mathrm{n}=13)$ & ODP $(\mathrm{n}=13)$ & P-value \\
\hline Operation time, min $^{\mathrm{a}}$ & $290.2 \pm 114.6$ & $337.3 \pm 130.7$ & 0.338 \\
Estimated blood loss, $\mathrm{ml}^{\mathrm{a}}$ & $122.3 \pm 171.8$ & $649.2 \pm 692.6$ & 0.019 \\
Blood transfusion, $\mathrm{n}(\mathrm{no}: \mathrm{yes})$ & $13: 0$ & $12: 1$ & $12: 1$ \\
Residual tumor, n (R0:R1) & $13: 0$ & $12: 1$ & 0.500 \\
Lymph node metastasis, n (no:yes) & $13: 0$ & 0.500 \\
\hline
\end{tabular}

${ }^{\mathrm{a}}$ Mean \pm SD. R0, no residual tumor; R1, microscopic residual tumor; LDP, laparoscopic distal pancreatectomy; ODP, open distal pancreatectomy.

Table III. Complications and postoperative hospital stay.

\begin{tabular}{lccc}
\hline Factor & LDP $(\mathrm{n}=13)$ & ODP (n=13) & P-value \\
\hline Overall complication, n (\%) & $4(31)$ & $7(54)$ & 0.234 \\
Hemorrhage, n (\%) & $0(0)$ & 0 & $(0)$ \\
Pancreatic fistula, n (\%) & $1(8)$ & $4(31)$ & - \\
Intraabdominal abscess, n (\%) & $2(15)$ & $2(15)$ & 0.161 \\
Surgical site infection, n (\%) & $2(15)$ & $6(46)$ & 0.101 \\
Postoperative hospital stay, days ${ }^{\mathrm{a}}$ & $10.7 \pm 7.4$ & $20.9 \pm 12.7$ & 0.022
\end{tabular}

${ }^{\mathrm{a}}$ Mean $\pm \mathrm{SD}$. LDP, laparoscopic distal pancreatectomy; ODP, open distal pancreatectomy.

Table IV. Metastatic case and recurrent cases.

\begin{tabular}{|c|c|c|c|c|c|c|c|c|}
\hline Case & Sex & $\begin{array}{l}\text { Age, } \\
\text { years }\end{array}$ & Functional or not & Grade & $\begin{array}{l}\text { Tumor } \\
\text { size, mm }\end{array}$ & $\begin{array}{l}\text { Procedure (positive } \\
\text { LN/harvest LN) }\end{array}$ & DFS, months & $\begin{array}{l}\text { Site of } \\
\text { recurrence }\end{array}$ \\
\hline \multicolumn{9}{|c|}{$\begin{array}{l}\text { Metastatic case on surgical specimen } \\
\text { by pathological findings }\end{array}$} \\
\hline 1 & Female & 50 & Gastrinoma & G1 & 6 & ODP (1/12) & 30 & No relapse \\
\hline \multicolumn{9}{|c|}{ Recurrent cases } \\
\hline 1 & Male & 43 & Non functional & NEC & 41 & $\mathrm{ODP}(0 / 8)$ & 1 & Liver and lung \\
\hline 2 & Male & 41 & Non functional & NEC & 20 & ODP (0/17) & 21 & Liver \\
\hline
\end{tabular}

DFS, disease-free survival; LN, lymph node; NEC, neuroendocrine carcinoma; ODP, open distal pancreatectomy.

\section{Discussion}

Recently, laparoscopic surgery and robotic surgery are increasingly being performed in some developed countries on patients with various gastrointestinal and pancreatic NETs. Although there have been very few reports that study the safety and long-term prognosis of laparoscopic surgery for NET in the gastrointestinal tract, conventional laparoscopic surgery that is performed for esophageal, gastric and colon cancer, and which requires systemic lymph node dissection, has achieved results comparable to open surgery. Based on these results, it is now considered that NET can be safely performed (14-16). In our analysis, LDP performed for PNET with small tumor size $(<2 \mathrm{~mm})$ was comparable to the results of the ODP; therefore, partial resection was performed in many cases. Furthermore, in situations where the surgical technique was similar, LDP tended to result in significantly less bleeding and shorter operation times than that with open surgery. However, this was not true when the tumor diameter was extremely large. The postoperative complications were not different between the two groups; however, the postoperative hospitalization period was significantly shorter in the LDP group. Of note, some of the previous studies on low malignant tumor also demonstrated that LDP shows perioperative outcomes and long-term prognosis that is either equal or better than that in ODP (17-19). From the results of this study and others, we believe that LDP appears to be safe and minimally invasive and may become more common in patients with PNET who do not require systemic lymphadenectomy or vascular resection. 
In this context, it is essential to discussion the lymph node metastasis and lymph node dissection of PNET. It is noteworthy that lymph node metastasis is seldom identified because $>90 \%$ of insulinomas are benign (20). Therefore, enucleation without lymph node dissection is recommended if it has no malignant findings and can be performed safely without damage to the main pancreatic duct (6-8). On the other hand, distal pancreatectomy is recommended when it is in close proximity to the main pancreatic duct. In addition, other functional NETs have high malignancy and poor prognosis (21-29). Of note, despite the rate of lymph node metastasis in gastrinoma being as high as $60 \%$ or even higher, improvement of prognosis by dissection has been reported $(30,31)$. Even in our data, one patient with gastrinoma which was just only $6 \mathrm{~mm}$ G1 tumor underwent partial pancreatectomy and lymph node dissection with long-term disease-free survival despite lymph node metastasis being found by pathology. Recently, there are some reports that it is safe to follow-up small nonfunctional NET with a tumor diameter of $<2 \mathrm{~cm}$ (9-13). On the other hand, lymph node metastasis has been reported even when the tumor diameter is $<1 \mathrm{~cm}$ (32-34). However, this includes the poorly differentiated tumors and requires careful attention in their interpretation. In our data, one patient who relapsed had a high grade NEC tumor with a diameter of $20 \mathrm{~mm}$. Further, lymph node metastasis of G1 PNET of $<1 \mathrm{~cm}$ has been reported to be extremely low (32-34). However, in such cases, the tumor size is either too small or FNA is too difficult, which results in the PNET grade not being diagnosed before surgery. Furthermore, PNEC resection results and postoperative prognostic factors have remained unreported, and the surgical indication for PNEC is still unclear from the guidelines. Two cases were found to have recurrence though distal pancreatectomy with numerous lymph nodes around the pancreas was performed (Table IV). Therefore, we could not mention to the lymph node dissection for PNEC.

Hence, laparoscopic pancreatectomy with lymphadenectomy around the pancreas, which is a minimally invasive procedure, could be the standard procedure, and an effective surgical technique for this approach is required for low-malignancy PNET. In other words, insulinoma and nonfunctional PNET $<2 \mathrm{~cm}$ are good indications of laparoscopic pancreatectomy with lymph node dissection around the pancreas, and introducing laparoscopic pancreatectomy to an inexperienced institution is a good opportunity.

Our report has the limitations of being a retrospective analysis of a single institution and involving a relatively small sample size. However, the strength of the analysis is that these are valuable individual findings of rare cancer.

In conclusion, although LDP has not sufficiently examined and accumulated evidence on long-term treatment results, it is clearly minimally invasive. In particular, it is considered to be one of the important treatment options in such a PNET region in which various range of malignancy for selected patients.

\section{Acknowledgements}

Not applicable.

\section{Funding}

No funding was received.

\section{Availability of data and materials}

The datasets used and/or analyzed during the current study are available from the corresponding author on reasonable request.

\section{Authors' contributions}

HShio, YS and TG analyzed and interpreted the patient data on PNET. HShio and YS wrote the manuscript. HShib, YS, TG and TI made substantial contributions in data analysis and interpretation. HShib, TH, JY, KF and SO helped in acquiring the data for the work. HShio and TI conceived the concept and designed the study. HShio and YS were responsible for assessing and confirming the authenticity of all raw data. TI critically revised the article. All authors read and approved the final manuscript.

\section{Ethics approval and consent to participate}

The study protocol was approved by the Ethics Committee of The Jikei University School of Medicine [approval no. 27-177(8062)], and written informed consent was obtained from each patient.

\section{Patient consent for publication}

Written informed consent was obtained from all subjects for publication of the present study. A copy of the written consent is available for review upon requests.

\section{Competing interests}

The authors declare that they have no competing interests.

\section{References}

1. Batukbhai BDO and De Jesus-Acosta A: The molecular and clinical landscape of pancreatic neuroendocrine tumors. Pancreas 48: 9-21, 2019

2. Ries LAG, Young JL, Keel GE, Eisner MP, Lin YD and Horner M-J (eds): SEER Survival Monograph: Cancer Survival Among Adults: U.S. SEER Program, 1988-2001, Patient and Tumor Characteristics. National Cancer Institute, SEER Program, NIH Pub. No. 07-6215, Bethesda, MD, 2007.

3. Ito $T$, Igarashi $H$, Nakamura K, Sasano H, Okusaka T, Takano K, Komoto I, Tanaka M, Imamura M, Jensen RT, et al: Epidemiological trends of pancreatic and gastrointestinal neuroendocrine tumors in Japan: A nationwide survey analysis. J Gastroenterol 50: 58-64, 2015.

4. Shah NP: NCCN guidelines updates: Discontinuing TKI therapy in the treatment of chronic myeloid leukemia. J Natl Compr Canc Netw 17: 611-613, 2019.

5. Zandee WT and de Herder WW: The evolution of neuroendocrine tumor treatment reflected by ENETS Guidelines. Neuroendocrinology 106: 357-365, 2018.

6. Hirshberg B, Cochran C, Skarulis MC, Libutti SK, Alexander HR, Wood BJ, Chang R, Kleiner DE and Gorden P: Malignant insulinoma: Spectrum of unusual clinical features. Cancer 104: 264-272, 2005.

7. Roldo C, Missiaglia E, Hagan JP, Falconi M, Capelli P, Bersani S, Calin GA, Volinia S, Liu CG, Scarpa A and Croce CM: MicroRNA expression abnormalities in pancreatic endocrine and acinar tumors are associated with distinctive pathologic features and clinical behavior. J Clin Oncol 24: 4677-4684, 2006.

8. Klöppel G, Couvelard A, Perren A, Komminoth P, McNicol AM, Nilsson O, Scarpa A, Scoazec JY, Wiedenmann B, Papotti M, et al: ENETS consensus guidelines for the standards of care in neuroendocrine tumors: Towards a standardized approach to the diagnosis of gastroenteropancreatic neuroendocrine tumors and their prognostic stratification. Neuroendocrinology 90: 162-166, 2009. 
9. Choi JH, Choi YH, Kang J, Paik WH, Lee SH, Ryu JK and Kim YT: Natural history of small pancreatic lesions suspected to be nonfunctioning pancreatic neuroendocrine tumors. Pancreas 47: 1357-1363, 2018.

10. Rosenberg AM, Friedmann P, Del Rivero J, Libutti SK and Laird AM: Resection versus expectant management of small incidentally discovered nonfunctional pancreatic neuroendocrine tumors. Surgery 159: 302-309, 2016.

11. Jung JG, Lee KT, Woo YS, Lee JK, Lee KH, Jang KT and Rhee JC: Behavior of small, asymptomatic, nonfunctioning pancreatic neuroendocrine tumors (NF-PNETs). Medicine (Baltimore) 94: e983, 2015.

12. Gaujoux S, Partelli S, Maire F, D'Onofrio M, Larroque B, Tamburrino D, Sauvanet A, Falconi M and Ruszniewski P: Observational study of natural history of small sporadic nonfunctioning pancreatic neuroendocrine tumors. J Clin Endocrinol Metab 98: 4784-4789, 2013.

13. Lee LC, Grant CS, Salomao DR, Fletcher JG, Takahashi N, Fidler JL, Levy MJ and Huebner M: Small, nonfunctioning, asymptomatic pancreatic neuroendocrine tumors (PNETs): Role for nonoperative management. Surgery 152: 965-974, 2012.

14. Takatsu Y, Fukunaga Y, Nagasaki T, Akiyoshi T, Konishi T, Fujimoto Y, Nagayama S and Ueno M: Short- and long-term outcomes of laparoscopic total mesenteric excision for neuroendocrine tumors of the rectum. Dis Colon Rectum 60: 284-289, 2017.

15. Downs-Canner S, Van der Vliet WJ, Thoolen SJ, Boone BA, Zureikat AH, Hogg ME, Bartlett DL, Callery MP, Kent TS, Zeh HJ and Moser AJ: Robotic surgery for benign duodenal tumors. J Gastrointest Surg 19: 306-312, 2015.

16. Shiroshita $H$, Inomata $M$, Bandoh $T$, Uchida $H$, Akira $S$ Hashizume M, Yamaguchi S, Eguchi S, Wada N, Takiguchi S, et al: Endoscopic surgery in Japan: The 13th national survey (2014-2015) by the Japan Society for Endoscopic Surgery. Asian J Endosc Surg 12: 7-18, 2019.

17. Zhang J, Jin J, Chen S, Gu J, Zhu Y, Qin K, Zhan Q, Cheng D, Chen H, Deng X, et al: Minimally invasive distal pancreatectomy for PNETs: Laparoscopic or robotic approach? Oncotarget 8: 33872-33883, 2017.

18. Fernández-Cruz L, Molina V, Vallejos R, Jiménez Chavarria E, Lõpez-Boado MA and Ferrer J: Outcome after laparoscopic enucleation for non-functional neuroendocrine pancreatic tumours. HPB (Oxford) 14: 171-176, 2012.

19. Haugvik SP, Gaujoux S, Røsok B, Gladhaug IP, Dousset B and Edwin B: Laparoscopic versus open pancreas resection for neuroendocrine tumours: Need for evaluation of oncological outcomes. HPB (Oxford) 16: 871, 2014.

20. de Herder WW: Insulinoma. Neuroendocrinology 80 (Suppl 1): S20-S22, 2004.

21. Ghaferi AA, Chojnacki KA, Long WD, Cameron JL and Yeo CJ: Pancreatic VIPomas: Subject review and one institutional experience. J Gastrointest Surg 12: 382-393, 2018.
22. Patel FB, Khagi S, Daly KP, Lechan RM, Ummaritchot V and Saif MW: Pancreatic neuroendocrine tumor with ectopic adrenocorticotropin production: A case report and review of literature. Anticancer Res 33: 4001-4005, 2013.

23. Garbrecht N, Anlauf M, Schmitt A, Henopp T, Sipos B, Raffel A, Eisenberger CF, Knoefel WT, Pavel M, Fottner C, et al: Somatostatin-producing neuroendocrine tumors of the duodenum and pancreas: Incidence, types, biological behavior, association with inherited syndromes, and functional activity. Endocr Relat Cancer 15: 229-241, 2008.

24. Wermers RA, Fatourechi V, Wynne AG, Kvols LK and Lloyd RV: The glucagonoma syndrome: Clinical and pathologic features in 21 patients. Medicine (Baltimore) 75: 53-63, 1996.

25. Öberg K: Pancreatic endocrine tumors. Semin Oncol 37: 594-618, 2010.

26. Kuo SC, Gananadha S, Scarlett CJ, Gill A and Smith RC: Sporadic pancreatic polypeptide secreting tumors (PPomas) of the pancreas. World J Surg 32: 1815-1822, 2008.

27. Soga J: Endocrinocarcinomas (carcinoids and their variants) of the duodenum. An evaluation of 927 cases. J Exp Clin Cancer Res 22: 349-363, 2003.

28. Fendrich V, Waldmann J, Bartsch DK and Langer P: Surgical management of pancreatic endocrine tumors. Nat Rev Clin Oncol 6: 419-428, 2009

29. Falconi M, Eriksson B, Kaltsas G, Bartsch DK, Capdevila J, Caplin M, Kos-Kudla B, Kwekkeboom D, Rindi G, Klöppel G, et al: ENETS consensus guidelines update for the management of patients with functional pancreatic neuroendocrine tumors and non-functional pancreatic neuroendocrine tumors. Neuroendocrinology 103: 153-171, 2016.

30. Giovinazzo F, Butturini G, Monsellato D, Malleo G, Marchegiani G and Bassi C: Lymph nodes metastasis and recurrences justify an aggressive treatment of gastrinoma. Updates Surg 65: 19-24, 2013.

31. Bartsch DK, Waldmann J, Fendrich V, Boninsegna L, Lopez CL, Partelli S and Falconi M: Impact of lymphadenectomy on survival after surgery for sporadic gastrinoma. Br J Surg 99: 1234-1240, 2012

32. Jutric Z, Grendar J, Hoen HM, Cho SW, Cassera MA, Newell PH, Hammill CW, Hansen PD and Wolf RF: Regional metastatic behavior of nonfunctional pancreatic neuroendocrine tumors: Impact of lymph node positivity on survival. Pancreas 46: 898-903, 2017.

33. Curran T, Pockaj BA, Gray RJ, Halfdanarson TR and Wasif N: Importance of lymph node involvement in pancreatic neuroendocrine tumors: Impact on survival and implications for surgical resection. J Gastrointest Surg 19: 152-160, 2015.

34. Gratian L, Pura J, Dinan M, Roman S, Reed S and Sosa JA: Impact of extent of surgery on survival in patients with small nonfunctional pancreatic neuroendocrine tumors in the United States. Ann Surg Oncol 21: 3515-3521, 2014. 